\title{
EDUKASI LITERASI MANUSIA DAN MODEL PEMBELAJARAN
}

\author{
Suyatmini'), Titik Ulfatun"1), Kardiyem²), Yovi Annang Setiyawan¹), Arnida Kusumaningtyas') \\ 1)Pendidikan Akuntansi, Fakultas Keguruan dan IImu Pendidikan, Universitas Muhammadiyah Surakarta, Surakarta, \\ Jawa Tengah, Indonesia \\ 2)Pendidikan Ekonomi, Fakultas Ekonomi, Universitas Negeri Semarang, Semarang, Jawa Tengah, Indonesia
}

Corresponding author : Titik Ulfatun

E-mail : titik.ulfatun@ums.ac.id

\section{Diterima 01 November 2021, Disetujui 05 November 2021}

\begin{abstract}
ABSTRAK
Era Revolusi Industri 4.0 dan Masyarakat 5.0 membawa tantangan bagi dunia pendidikan termasuk pendidikan kejuruan. Pendidikan kejuruan harus mampu menyiapkan lulusannya untuk bersaing pada era tersebut. Untuk dapat bersaing, peserta didik perlu dibekali dengan literasi baru yaitu literasi data, literasi teknologi, dan literasi manusia. Literasi manusia diyakini menjadi literasi yang paling penting karena literasi ini menjaga seseorang tetap dalam kodratnya sebagai manusia di tengah gempuran kecanggihan teknologi yang ada. Penguatan literasi manusia dapat dilakukan melalui penerapan model pembelajaran yang sesuai dengan karakteristik pendidikan kejuruan. Kegiatan ini bertujuan untuk mengenalkan literasi manusia dan model pembelajarannya kepada Bapak/lbu Guru SMK Muhammadiyah 2 Klaten Utara, khususnya jurusan Akuntansi dan Keuangan Lembaga. Program ini dilaksanakan dalam bentuk edukasi dimana tim pengabdian memberikan pendidikan tentang literasi manusia dan model pembelajaran kepada Bapak/lbu Guru. Hasil kegiatan menunjukkan bahwa Bapak/lbu Guru lebih mengenal literasi manusia dan model pembelajaran yang dapat diterapkan untuk menguatkan literasi manusia pada siswa.
\end{abstract}

Kata kunci: literasi manusia; model pembelajaran; literasi baru.

\begin{abstract}
The Industrial Revolution 4.0 and Society 5.0 era have brought challenges to education, including vocational education. Vocational education must be able to prepare graduates to compete in those era. To be able to compete, students need to be equipped with new literacies, namely data literacy, technological literacy, and human literacy. Human literacy is believed as the most important literacy because this literacy keeps a person in his nature as a human in the midst of the sophisticated technology development. Strengthening human literacy can be done through the implementation of learning models that are in accordance with the characteristics of vocational education. This activity aims to introduce human literacy and learning models used to reinforce it to teachers at SMK Muhammadiyah 2 Klaten Utara, especially those who teach Accounting and Institution Finance. This program is carried out in the form of education where the team provides education about human literacy and learning models to teachers. The results of the activity show that teachers get more knowledge about human literacy for students and what kind of learning models that can be used to reinforce the literacy.
\end{abstract}

Keywords: human literacy; learning models; new literacies.

\section{PENDAHULUAN}

Revolusi Industri 4.0 dan Masyarakat 5.0 memberikan tantangan tersendiri bagi dunia pendidikan, khususnya Sekolah Menengah Kejuruan (SMK). Tantangan tersebut dapat berupa aspek teknis, sumber daya, dan teknologi serta penguasaannya (Dwijonagoro et al., 2019). Tantangan yang lain yaitu SMK dituntut untuk memperbaiki kualitas dan mampu untuk menghadapi iklim yang semakin kompetitif sehingga lulusan SMK diharapkan dapat menjadi lulusan yang kompeten, produktif, dan profesional (Pangaribuan, 2018).
Beberapa solusi sudah ditawarkan agar SMK siap dalam menghadapi tantangan Revolusi Industri 4.0 dan Masyarakat 5.0. Salah satunya adalah kurikulum pendidikan kejuruan perlu untuk dikembangkan agar sesuai dengan era Revolusi Industri 4.0 dan relevan dalam menjawab kebutuhan keterampilan baru, misalnya keterampilan dalam coding, big data, dan artificial intelligence (Verawadina et al., 2019). Lebih lanjut lagi, mereka menyatakan bahwa kurikulum perlu memuat penguasaan keterampilan 4.0 seperti literasi data, literasi teknologi, dan literasi manusia. Pemerintah 
perlu mencanangkan penerapan gerakan literasi baru yang meliputi literasi digital, literasi teknologi, dan literasi manusia (Dwijonagoro et al., 2019). Solusi yang ditawarkan di atas lebih menitikberatkan pada kurikulum yang relevan dan penguasaan literasi baru yaitu literasi data, literasi teknologi, dan literasi manusia.

Diantara ketiga literasi baru di atas, literasi manusia menjadi topik bahasan yang menarik. Literasi ini ditujukan agar manusia berfungsi dengan baik di lingkungannya (Ahmad, 2018). Literasi manusia (human literacy) sebagaimana disebutkan oleh Aoun (2017) mengajarkan seseorang tentang perikemanusiaan, komunikasi, dan desain.

Dalam konteks SMK, keberadaan literasi manusia sangat diperlukan untuk menghasilkan lulusan SMK yang mempunyai keterampilan komunikasi dan desain yang baik dengan tetap menjunjung tinggi perikemanusiaan, sehingga mereka dapat siap bersaing di dalam dunia kerja pada era Revolusi Industri 4.0. Sebuah studi yang dilakukan oleh Lestari \& Santoso (2019) mengungkapkan bahwa literasi manusia bersama-sama dengan literasi digital dan literasi teknologi mempunyai pengaruh yang positif dan signifikan sebesar $54,7 \%$ terhadap kesiapan kerja pada mahasiswa. Jika dianalogikan, maka hal ini juga dapat berlaku pada siswa SMK yang memang disiapkan untuk langsung bekerja setelah lulus nantinya.

Selain itu, berdasarkan hasil wawancara yang dilakukan kepada dua narasumber menyebutkan bahwa penerapan model pembelajaran yang ada pada saat sekarang ini belum sepenuhnya dapat menguatkan literasi manusia pada siswa. Kedua narasumber tersebut merupakan guru produktif yang mengampu mata pelajaran Akuntansi Dasar pada salah satu sekolah negeri dan swasta.

Penguatan literasi manusia di dalam dunia pendidikan dapat dilakukan melalui kegiatan pembelajaran dengan menerapkan model pembelajaran yang sesuai. Misalnya, penggunaan model pembelajaran berbasis masalah terbukti dapat secara otomatis meningkatkan literasi manusia seperti yang dipersepsikan oleh partisipan (Rusydiyah \& Jazil, 2020). Oleh karena itu, diperlukan pemahaman yang lebih baik mengenai model pembelajaran Akuntansi, khususnya disesuaikan dengan materi pokok yang disampaikan sehingga penguatan literasi manusia dapat tercapai. Selain itu, pemahaman yang mendalam mengenai literasi manusia termasuk pokok-pokok pikirannya juga diperlukan oleh pendidik. Adanya program edukasi ini diharapkan mampu lebih mengenalkan literasi manusia dan model pembelajarannya kepada Bapak/lbu guru.

\section{METODE}

Program pengabdian masyarakat ini dilaksanakan pada tanggal 14 Agustus 2021 secara daring melalui zoom meeting. Kegiatan ini dilakukan dalam bentuk kegiatan edukasi kepada Bapak/lbu guru, khususnya jurusan Akuntansi dan Keuangan Lembaga di SMK Muhammadiyah 2 Klaten Utara. Berikut adalah langkah-langkah dalam pelaksanaan kegiatan pengabdian ini:

a. Melakukan koordinasi dengan pihak sekolah terkait dengan kegiatan pengabdian, termasuk penentuan waktu dan jadwal kegiatan.

b. Menyiapkan materi edukasi tentang literasi manusia dan model pembelajaran berupa PowerPoint.

c. Melaksanakan kegiatan pengabdian pada hari Sabtu, 14 Agustus 2021 mulai pukul 09.00 WIB - 12.30 WIB.

\section{HASIL DAN PEMBAHASAN}

Secara keseluruhan, kegiatan pengabdian ini berjalan dengan baik dan lancar. Acara ini merupakan acara bersama dimana Prodi Pendidikan Akuntansi dan SMK Muhammadiyah 2 Klaten Utara bekerja sama untuk mengadakan pengabdian masyarakat sebagai mitra. Jadwal kegiatan terdiri dari pembukaan serta penyampaian materi dan tanya jawab.

Mengingat kegiatan pengabdian ini dilakukan secara paralel (peserta nantinya akan dipecah ke dalam dua kelompok), maka sebelumnya diadakan terlebih dahulu sesi pembukaan bersama. Acara dimulai dengan membaca basmalah sebagai pembukaan dan dilanjutkan dengan sambutan-sambutan. Sambutan yang pertama yaitu dari Kaprodi Pendidikan Akuntansi FKIP UMS dan dilanjutkan dengan sambutan Kepala SMK Muhammadiyah 2 Klaten Utara.

Total keseluruhan peserta kegiatan pengabdian masyarakat ini yaitu 45 peserta yang terdiri dari Bapak/lbu guru SMK Muhammadiyah 2 Klaten Utara baik guru adapatif, normatif, dan produktif. Sebelum penyampaian materi dilakukan, peserta dibagi menjadi dua kelompok breakout room yaitu Room A untuk Bapak/lbu Guru yang fokus mengajarnya berkaitan dengan kompetensi keahlian Akuntansi dan Keuangan Lembaga serta Room B untuk Bapak/lbu yang tertarik pada bahasan topik pengabdian yang umum seperti tentang teaching factory. Tim pengabdian kami memaparkan materi pada Room A yang diikuti oleh 20 peserta. Materi 
tentang literasi manusia dan model pembelajaran disampaikan terlebih dahulu kemudian dilanjutkan dengan sesi tanya jawab. Istilah new literacies atau literasi baru diperkenalkan oleh Aoun (2017) dimana ia menyatakan bahwa lulusan pada masa depan akan membutuhkan tambahan tiga literasi baru (literasi data, literasi teknologi, dan literasi manusia) selain literasi lama (literasi membaca, literasi menulis, dan literasi matematika). la menyatakan bahwa lulusan tersebut akan hidup dan bekerja dalam dunia yang mengandalkan big data, konektivitas, dan informasi yang instan dari perangkat elektronik mereka dalam setiap click dan touch yang mereka lakukan. Oleh karena itu, ia menjelaskan bahwa literasi data diperlukan untuk membaca, menganalisis, dan menggunakan gelombang informasi yang terus meningkat ini. la juga menyampaikan bahwa literasi teknologi memberikan dasar bagi lulusan dalam hal coding dan prinsip-prinsip teknik, sehingga mereka tahu bagaimana mesin-mesin mereka bekerja. Lebih lanjut lagi, ia menyebutkan bahwa literasi manusia mengajari lulusan tentang perikemanusiaan, komunikasi, dan desain yang memungkinkan mereka menjalankan fungsinya dalam lingkungan manusia. Istilah literasi baru (literasi data, literasi teknologi, dan literasi manusia) inilah yang kemudian menjadi topik bahasan hangat dalam dunia pendidikan Indonesia, terutama jika dikaitkan dengan kesiapan dalam menghadapi Revolusi Industri 4.0 dan Masyarakat 5.0.

Aoun (2017) menyebutkan bahwa dari ketiga literasi baru di atas, literasi manusia merupakan literasi yang paling penting. Menurutnya, hal ini karena literasi manusia memperlengkapi seseorang untuk lingkungan sosial, memberikan kekuatan untuk berkomunikasi, untuk terlibat dengan orang lain, dan memanfaatkan kapasitas manusia yang dimiliki untuk keanggunan dan keindahan. Berikut adalah beberapa pokok pikiran tentang literasi manusia yang disampaikan oleh Aoun (2017):

a. Kemanusiaan merupakan salah satu wadah yang tepat untuk membina manusia seutuhnya.

b. Para profesional membutuhkan pemahaman yang kuat tentang literasi manusia karena terlepas dari dunia digital yang ada, mereka hidup dan berinteraksi dengan manusia.

c. Dalam dunia kerja, keterampilan seperti brainstorming, bernegosiasi, dan membuat keputusan bersama menjadi semakin penting.

d. Pemahaman tentang keragaman dapat memperkaya dan memperluas pemikiran siswa serta membangun literasi manusia yang berharga.

e. Selain kerukunan, seorang juga harus tahu cara berkomunikasi dan memotivasi orang lain.

Dalam dunia pendidikan, penguatan literasi manusia bagi siswa dapat dilakukan melalui berbagai macam cara. Sari, Rejekiningsih, \& Muchtarom (2020) menyatakan bahwa literasi manusia sebagai strategi pendidikan dapat diterapkan melalui program-program yang berorientasi pada penguatan pendidikan karakter di sekolah. Mereka mencontohkan program tersebut yaitu kegiatan pendampingan, kegiatan pembiasaan siswa di sekolah atau secara langsung melibatkan mereka dalam kegiatan sosial yang berkaitan dengan materi pelajaran, dan mengintegrasikannya secara langsung dalam pembelajaran. Selain itu, penguatan literasi manusia pada siswa juga dapat dilakukan melalui model pembelajaran yang digunakan.

$$
\text { Model pembelajaran merupakan }
$$

kerangka konseptual dan operasional pembelajaran yang memiliki nama, ciri, urutan logis, pengaturan, dan budaya (Permendikbud RI Nomor 103 Tahun 2014). Selanjutnya, dalam Lampiran juga disebutkan bahwa model pembelajaran yang direkomendasikan yaitu discovery learning, project-based learning, problem-based learning, dan inquiry learning.

$$
\text { Dalam ranah sosial, Joyce \& Weil }
$$
(2003) menyebutkan lima jenis model pengajaran yang dapat digunakan oleh guru, yaitu: partners in learning, group investigation, role playing, dan jurisprudential inquiry. Dengan melihat karakteristik literasi manusia itu sendiri, penulis merasa bahwa model pengajaran dalam ranah sosial ini cocok diimplementasikan untuk menguatkan literasi manusia pada siswa. Berikut adalah penjelasan social models dari Joyce \& Weil (2003):

a. Partners in learning

Model ini dapat berupa memberikan tugas pembelajaran yang sederhana secara berpasangan atau bisa juga dengan mengorganisasikan kelas dan bahkan sekolah dalam masyarakat belajar untuk mengedukasi diri mereka sendiri.

b. Group investigation

Model ini mengarahkan siswa untuk mendefinisikan masalah kemudian mengeksplorasi berbagai sudut pandang dari masalah tersebut. Para siswa dapat belajar bersama mengenai informasi, ide, dan keterampilan dimana hal ini sekaligus meningkatkan kompetensi sosial siswa.

c. Role playing

Model ini mengarahkan siswa untuk memahami perilaku sosial, peran mereka 
dalam interaksi sosial, dan cara memecahkan masalah secara lebih efektif. Selain itu, siswa diminta untuk bermain tentang konflik, belajar dari mengambil peran orang lain, dan mengamati perilaku sosial.

d. Jurisprudential inquiry

Model ini mengarahkan siswa mempelajari kasus-kasus tentang masalah sosial pada bidang-bidang di mana kebijakan publik perlu dibuat (misalnya tentang isu-isu keadilan dan kesetaraan, kemiskinan, dan kekuasaan). Mereka dibimbing untuk mengidentifikasi isu-isu tersebut serta cara untuk menghadapinya dan alasan memilih cara tersebut.

Berikut adalah gambar salah satu slide materi yang disampaikan (lihat Gambar 1) dan screenshot peserta kegiatan (lihat Gambar 2).

\section{Peta Konsep}

\section{(6) UMS}

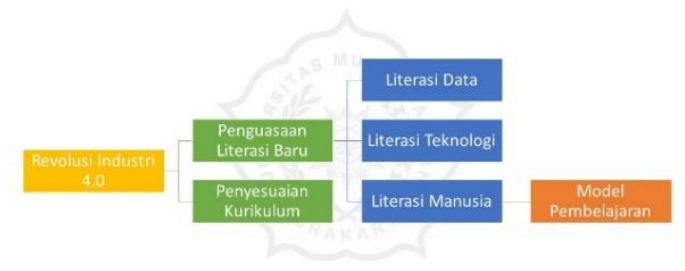

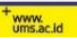

Gambar 1. Salah Satu Slide Materi

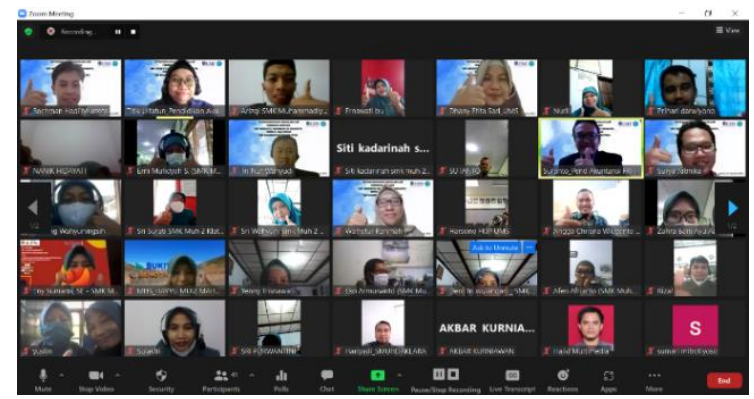

Gambar 2. Salah Satu Screenshot Peserta Kegiatan

Pada akhir kegiatan, peserta melakukan refleksi berkaitan dengan kegiatan yang telah dilakukan. Mereka menyatakan bahwa dengan adanya kegiatan ini, mereka lebih mengenal tentang literasi manusia dan model pembelajaran yang dapat digunakan untuk menguatkan literasi manusia pada siswa. Keterbatasan dalam pengabdian ini yaitu tim pengabdian tidak memberikan pretest dan posttest untuk mengetahui adanya peningkatan pengetahuan. Peningkatan pengetahuan diketahui hanya dari hasil refleksi peserta pada akhir kegiatan.

\section{SIMPULAN DAN SARAN}

Kegiatan pengabdian masyarakat yang bertujuan untuk mengenalkan literasi manusia dan model pembelajarannya ini berlangsung dengan lancar. Kegiatan dimulai dengan pembukaan lalu dilanjutkan dengan penyampaian materi literasi manusia dan model pembelajaran. Pada akhir kegiatan, peserta mengkonfirmasi bahwa mereka lebih mengenal literasi manusia dan model pembelajaran yang dirasa cocok digunakan untuk menguatkan literasi manusia pada siswa. Kegiatan ini sebaiknya dilaksanakan dengan memberikan pretest dan posttest sebagai bukti adanya peningkatan pengetahuan yang lebih valid.

\section{UCAPAN TERIMAKASIH}

Penulis mengucapkan terima kasih kepada Fakultas Keguruan dan IImu Pendidikan, Universitas Muhammadiyah Surakarta atas dukungan pendanaan yang diberikan

\section{DAFTAR RUJUKAN}

Ahmad, I. (2018). Proses pembelajaran digital dalam era Revolusi Industri 4.0 era disrupsi teknologi. Kementerian Riset, Teknologi, Dan Pendidikan Tinggi, 1-13.

Aoun, J. E. (2017). Robot-Proof: Higher Education in the Age of Artificial Intelligence. The MIT Press. https://opensourcebook.in/wpcontent/uploads/2020/04/19ele.pdf

Dwijonagoro, S., Ghufron, A., Khurniawan, A. W., Ismara, K. I., Setiadi, B. R., Damarwan, E. S., Rezani, R., Wibowo, A. E., Ratnawati, D., \& Panditatwa, P. (2019). Turbulensi pendidikan vokasi di era disrupsi 4.0 (B. R. Setiadi, A. E. Wibowo, \& M. A. Majid (eds.)). Direktorat Pembinaan Sekolah Menengah Kejuruan (DitPSMK).

https://psmk.kemdikbud.go.id/konten/458 5/turbulensi-pendidikan-vokasi-di-eradisrupsi-40

Joyce, B., \& Weil, M. (2003). Models of teaching (Fifth Edit). Prentice-Hall of India.

Lestari, S., \& Santoso, A. (2019). The roles of digital literacy, technology literacy, and human literacy to encourage work readiness of accounting education students in the fourth industrial revolution era. KnE Social Sciences, Internatio, 513527.

https://doi.org/10.18502/kss.v3i11.4031

Pangaribuan, P. (2018). Tantangan revolusi industri 4.0 untuk SMK. Direktorat Sekolah Menengah Kejuruan. https://smk.kemdikbud.go.id/konten/3854/ tantangan-revolusi-industri-40-untuk-smk 
Permendikbud RI Nomor 103 Tahun 2014 tentang Pembelajaran di Pendidikan Dasar dan Menengah

Rusydiyah, E. F., \& Jazil, S. (2020). Percepetions of Faculty of Education Students in Using Problem Based Learning to Increase Human Literacy. Journal of Talent Development and Excellence, 65-84. http://iratde.com/index.php/jtde/article/vie w/85

Sari, D. I., Rejekiningsih, T., \& Muchtarom, M. (2020). The concept of human literacy as civics education strategy to reinforce students' character in the era of disruption. Advances in Social Science, Education and Humanities Research, 397(3rd International Conference on Learning Innovation and Quality Education (ICLIQE 2019)), 1132-1141. https://doi.org/10.2991/assehr.k.200129.1 40

Verawadina, U., Jalinus, N., \& Asnur, L. (2019). Kurikulum pendidikan vokasi pada era Revolusi Industri 4.0. Jurnal Pendidikan, 20(1), 82-90. https://doi.org/10.33830/jp.v20i1.843.201 9 